\title{
Caen - Le Château
}

$n^{\circ} 3239$

Bénédicte Guillot

\section{(2) OpenEdition}

Journals

Édition électronique

URL : http://journals.openedition.org/adlfi/16894

ISSN : 2114-0502

Éditeur

Ministère de la culture

Référence électronique

Bénédicte Guillot, "Caen - Le Château », ADLFI. Archéologie de la France - Informations [En ligne], Basse-Normandie, mis en ligne le 16 mars 2016, consulté le 19 avril 2019. URL : http:// journals.openedition.org/adlfi/16894

Ce document a été généré automatiquement le 19 avril 2019

(c) Ministère de la Culture et de la Communication, CNRS 


\section{Caen - Le Château}

$n^{\circ} 3239$

\section{Bénédicte Guillot}

Lien Atlas (MCC) :

http://atlas.patrimoines.culture.fr/atlas/trunk/index.php?

ap_theme=DOM_2.01.02\&ap_bbox=-0.413;49.153;-0.331;49.216

1 En 1998, la ville de Caen a lancé un programme de conservation et de mise en valeur du château de Caen. Une opération d'archéologie préventive a eu lieu en 2005 à l'emplacement des actuelles salles du rempart. Une fouille programmée a été lancée en 2011 afin d'étudier un grand bâtiment mis en évidence en 2005 et se développant au sud des limites de fouille. Elle s'est poursuivie en 2012 et 2013, et se terminera en 2014.

2 À l'issue de cette troisième campagne de fouille, l'ensemble des niveaux postérieurs à la récupération des maçonneries de l'édifice a été étudié. Ces remblais, présents sur une épaisseur de 3,50 $\mathrm{m}$, correspondent en partie inférieure au démantèlement d'une partie des maçonneries à la fin du $\mathrm{Xv}^{\mathrm{e}}$ ou au début $d u \mathrm{XVI}^{\mathrm{e}}$ s., puis à la mise en place du mur du Cavalier servant à supporter une terrasse d'artillerie dans l'angle nord-ouest du château au cours $d u \mathrm{XVII}^{\mathrm{e}} \mathrm{s}$. Les fondations de ce mur, construit en moellons calcaires rectangulaires avec, à intervalle régulier, des harpes en grand appareil calcaire, reprennent le tracé du mur gouttereau nord de l'édifice.

3 Concernant le grand édifice, qui couvre une surface de près de $300 \mathrm{~m}^{2}$, les fouilles de l'été 2013 ont permis de confirmer l'existence d'un bâtiment à deux niveaux avec la mise au jour d'une maçonnerie orientée nord-sud. Ceci permet la présence, dans le tiers ouest, d'un espace de $90 \mathrm{~m}^{2}$ sur plus de $3 \mathrm{~m}$ de haut, accessible à l'origine par une porte dans l'angle nord-ouest. Le niveau de circulation de cet espace est constitué de terre battue. Il repose sur un ressaut de fondation interne du pignon, dont les fondations existent sur plus d' $1,50 \mathrm{~m}$ de haut.

4 Des restes d'un enduit de chaux ont été mis en évidence sur le pignon ouest avec, tracées en creux, des lignes permettant d'imiter un appareil de pierres. La datation de cet enduit 
n'a pu être déterminée et il pourrait s'agir d'un aménagement postérieur à la construction.

5 L'accès au niveau supérieur, probablement d'un seul tenant, se fait par la porte principale de l'édifice, large de 2,20 m, située au centre du pignon oriental et ouvrant sur la cour du château. L'hypothèse d'un sol en plancher pour ce niveau reste posée puisqu'aucun niveau de circulation n'existe, dans la portion dégagée, entre le terrain naturel et les premiers remblais issus de la démolition. Deux plots maçonnés, situés dans l'axe de la porte centrale, pourraient supporter ce plancher.

6 La moitié orientale du bâtiment a été complètement fouillée jusqu'à l'apparition du terrain naturel, constitué de plaquettes calcaires. De nombreuses fosses et trous de poteau sont creusés dans la roche, certains sont contemporains de la construction de l'édifice, tels les deux fosses, découvertes en 2012, ayant servi à éteindre la chaux vive avant son utilisation pour confectionner le mortier des maçonneries. Mais la plupart des structures fossoyées sont plus difficiles à identifier et certaines pourraient être antérieures à l'édifice, témoignant peut-être de l'utilisation du socle rocheux comme carrière à ciel ouvert.

7 La stratigraphie dans la moitié ouest est beaucoup plus importante, du fait du pendage $d u$ terrain naturel. Seuls des sondages, répartis le long du pignon ouest et dans la partie centrale, ont permis d'observer les niveaux jusqu'au ressaut de fondation des murs.

8 Au cours du Moyen Âge, une seconde ouverture à l'étage bas est percée dans l'angle sudouest, permettant un accès direct vers le sud. Au débouché de la porte, deux murets délimitent un petit espace, de moins de $2 \mathrm{~m}^{2}$, comprenant un dallage en galets calcaires et un accès vers le reste du bâtiment. La présence d'une auge en pierre dans cet espace renforce son identification comme un réduit pour un petit animal, comme un chenil par exemple.

9 Enfin, il faut signaler la mise en évidence d'une structure de type fosse ou tranchée, creusée dans le terrain naturel et qui est comblée à la fin du XII ${ }^{\mathrm{e}}$ s., probablement lors de la construction de l'édifice. Observée sur une petite surface, elle semble avoir une orientation nord-est - sud-ouest et une largeur d'environ 2,20 m. Le dégagement total de cette structure en 2014 permettra de statuer sur son utilisation, simple fosse d'extraction du sous-sol calcaire ou autre... 


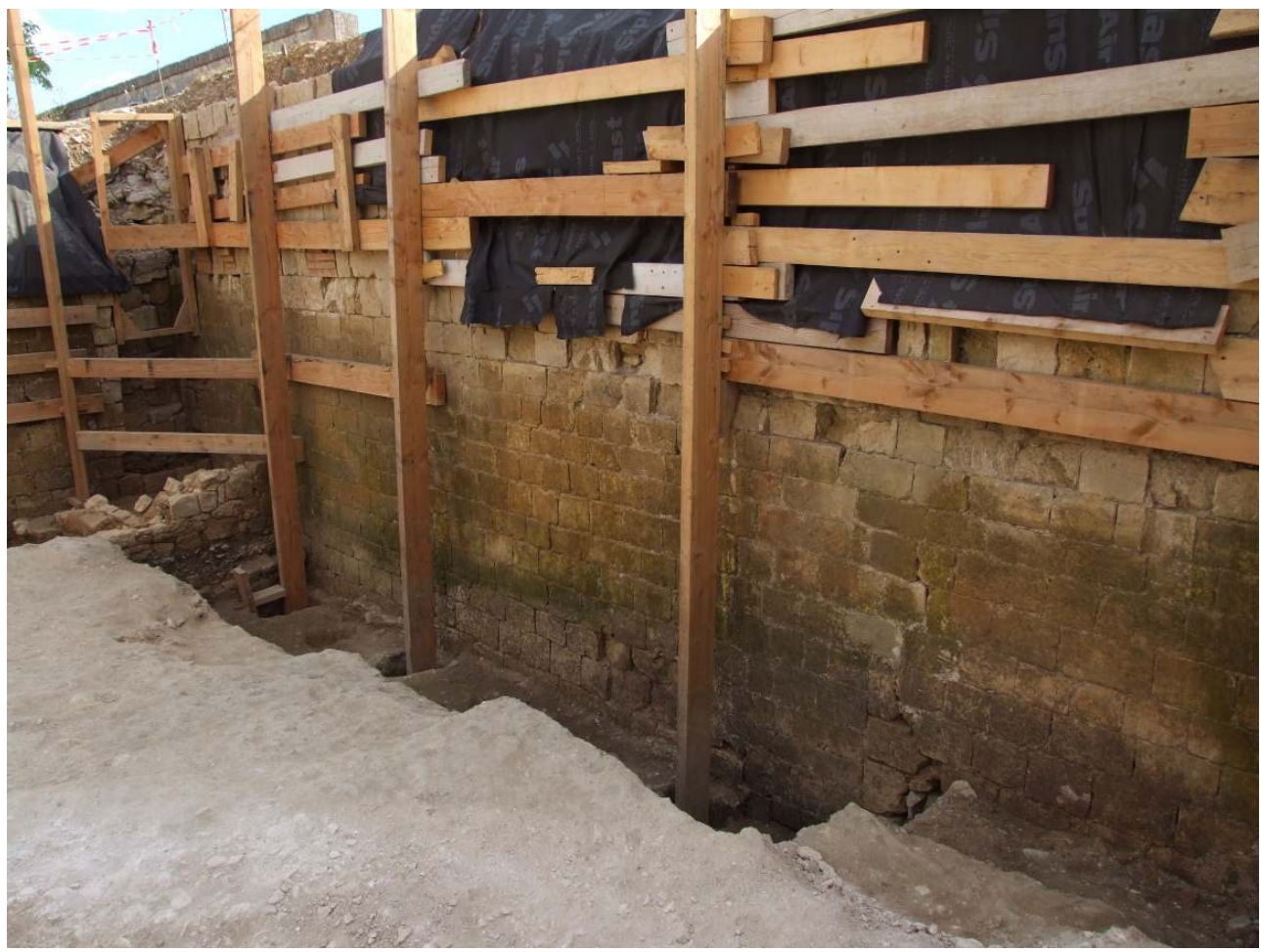

\section{Fig 01}

Vue générale du pignon ouest de l'édifice

Cliché : B. Guillot, Inrap/Craham

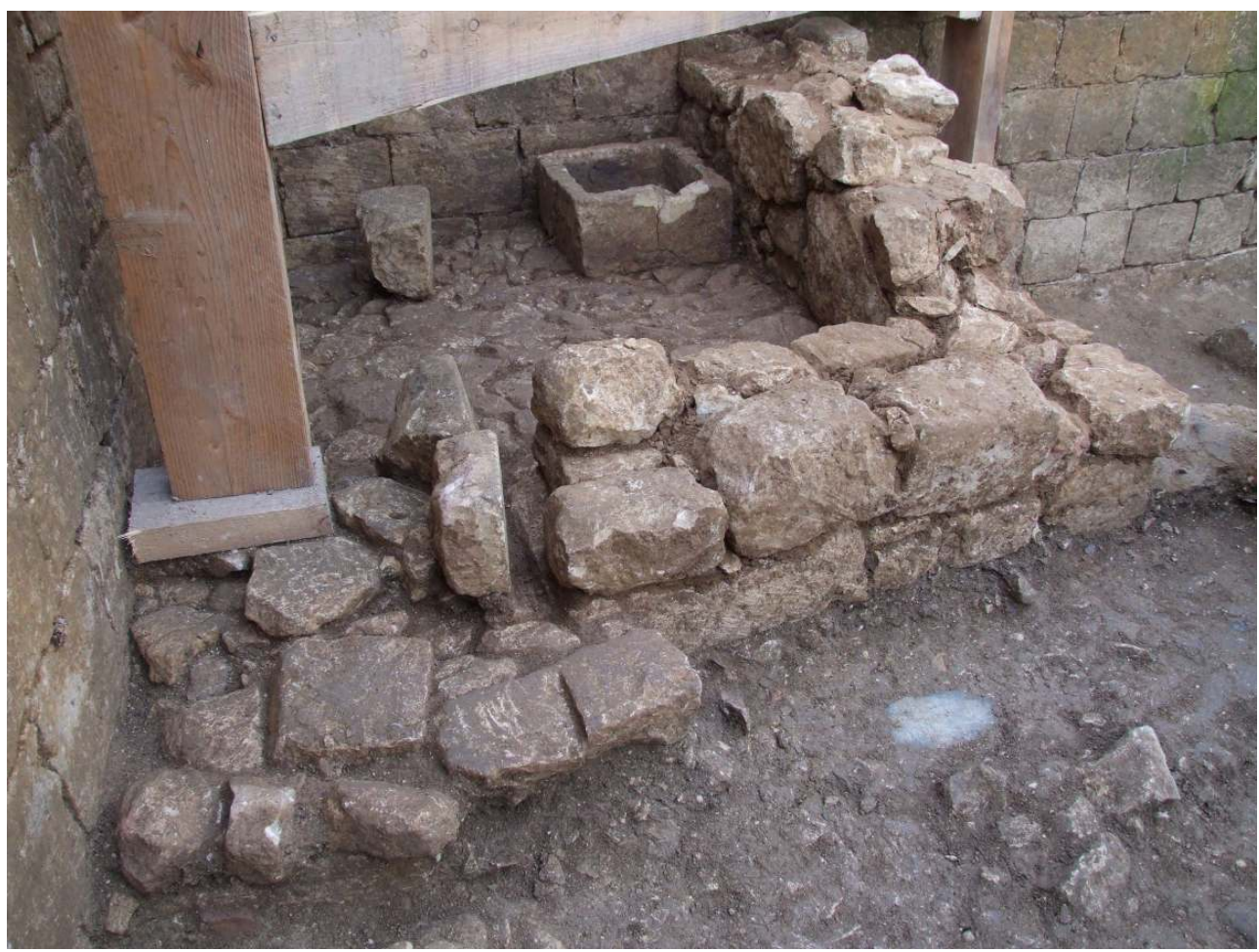




\section{Fig 02}

Détail du réduit installé dans l'angle sud-ouest de l'édifice

Cliché : B. Guillot, Inrap/Craham

INDEX

Index géographique : Basse-Normandie, Calvados (14), Caen

Mots-clés : bâti, maçonnerie, chenil, fosse

operation Fouille programmée (FP)

Index chronologique : Moyen Âge

\section{AUTEURS}

BÉNÉDICTE GUILLOT

Inrap 